\section{Evolutionary Medicine}

Kaitlyn Finneran ${ }^{1}$, Teresa Aoki ${ }^{2}$, Brendon K. Billings ${ }^{3}$, Maria J. Barnes ${ }^{4}$ and Muhammad A. Spocter ${ }^{1,3,5}$

${ }^{1}$ Department of Anatomy, Des Moines University, Des Moines, IA, USA

${ }^{2}$ Department of Internal Medicine, Des Moines

University, Des Moines, IA, USA

${ }^{3}$ School of Anatomical Sciences, University of the

Witwatersrand, Johannesburg, South Africa

${ }^{4}$ Department of Biochemistry and Nutrition, Des

Moines University, Des Moines, IA, USA

${ }^{5}$ Department of Biomedical Sciences, College of Veterinary Medicine, Iowa State University,

Ames, IA, USA

\section{Synonyms}

Darwinian medicine

\section{Definition}

Evolutionary medicine is a transdisciplinary field of study aimed at applying evolutionary concepts and thinking to our understanding of medicine.

\section{Introduction}

Unlike the traditional approach to medicine which is aimed at identifying and treating the proximate causes (i.e., symptoms) of disease, an evolutionary medicine approach is focused on identifying the evolutionary origins (ultimate cause) of a disease and to use this to help inform medical practice (Williams and Nesse 1991; Trevathan 2010; Ruhli and Henneberg 2013). Evidence in support of evolutionary medicine is provided by observers working in various fields, including cognitive science, anthropology, demography, biochemistry and molecular biology, and genetics. Evolutionary medicine thus offers a broader and more holistic perspective to medicine. The significance of using an evolutionary approach to medicine is highlighted by the tremendous insight gained from our understanding of antibiotic resistance (Davies and Davies 2010) and the rise in recent viral or bacterial outbreaks (e.g., Ebola, Measles, COVID-19). Interest in evolutionary medicine has grown exponentially (Alcock 2012) with this field contributing significantly toward our understanding of important topics in human health including immune function (Cooper and Herrin 2010; Litman and Cooper 2007), aging (Stearns et al. 2000; Stearns 1989), infectious disease (Ewald 1994; Schmid Hempel 2011), reproductive health (Trevathan 2011), behavioral and mental disorders (Keller and Nesse 2006; Nesse 1999), inflammation (Straub 
2012), diet (Chakravarthy and Booth 2004), and cancer (Merlo et al. 2006).

\section{History}

Neese and Williams (Williams and Nesse 1991) are credited with bringing about a resurgence of interest in the field of evolutionary medicine through their now classic articulation of the key concepts covered by a "Darwinian" approach. However, the field of evolutionary medicine has a much longer and often forgotten history dating back to some of the earliest champions of the comparative approach (Trevathan et al. 2008). Aside from the seminal work of Charles Darwin, to whom we owe the foundations of our current understanding of evolution, one of the earliest proponents of evolutionary medicine was in fact Charles's grandfather, Erasmus Darwin. Erasmus was one of the first physicians to think about the impact of nature on humans and published a taxonomic catalog of known diseases of his day, along with their causes and treatments (Darwin 1794-1796). In 1926, physician Dudley J. Morton expounded on Darwin's views and stated that diseases should be viewed through the lens of human variation and adaptation and that clinicians should aim to understand the evolutionary basis of adaptation to disease (Morton 1926). While these early calls to action linking evolution to medicine were somewhat forgotten in the early part of the twentieth century, what emerged from them was a growing interest in understanding human adaptations to particular environments and its impact on the underlying anatomy and physiology. By the middle of the twentieth century, this emerging research area was further enhanced by studies of sickle cell disease in various populations, demonstrating that variation in human hemoglobin structure was associated with immunity to the malaria parasite (Allison 1953, 1954; Barnicot, Ikin, and Mourant 1954). Furthermore, the impact of humans on the environment and our role in disease propagation was highlighted by further studies emerging from this field, highlighting the influence of human agriculture on the breeding behavior and distribution of the malarial parasite (Livingston 1958). In the later part of the twentieth century, questions in evolutionary medicine have extended upon these earlier themes to identify diseases of modernity (e.g., type 2 diabetes, hypertension, addiction) and their evolutionary origins as well as the role of human activities and industrialization in shaping disease progression (Trevathan 2010). Some of these topics include the appearance of novel metabolic processes such as lactose tolerance (Matthews et al. 2005), the genetic variations in the abilities of humans to process alcohol (Jornvall 1994), changes in the human skeleton (Schwidetsky 1962; Ruff 2002), changes in human body weight and height (Katmarzky and Leonard 1998), and changes in the size and number of human teeth (Brace et al. 1987). These and other microevolutionary changes to the human body likely resulted from environmental changes resulting from modern living (Ruhli and Henneberg 2013).

\section{Fundamentals of Evolutionary Medicine}

Before outlining some of the core principles of evolutionary medicine, it is important to remember the basic assumptions of Darwinian evolution and one of the auxiliary theories often used in evolutionary medicine. In order for a feature to be considered Darwinian in nature, (1) the feature must exhibit variability in phenotype, (2) this variability must be heritable (i.e., transmitted from parents to offspring), and (3) the feature must exhibit selective fitness (i.e., impact species reproduction and/or survival to reproductive age) (Boyd and Silk 2009). The auxiliary theory often used in evolutionary medicine is that of life history theory which recognizes that the growth, maintenance, and reproduction of the organism is determined by the differential allocation of energy budgets which are themselves influenced by Darwinian processes (Stearns 1989). While the scope of evolutionary medicine covers all known areas of human disease, Neese and Williams (Williams and Nesse 1991) originally described five major categories of evolutionary explanation to which "Darwinian medicine" could be applied. Recently, using an expert consensus approach, the components of evolutionary medicine have been expanded to include a more extensive list of core principles, aimed not only at focusing the teaching of evolutionary medicine but also at guiding 
ongoing research in this field (Grunspan et al. 2018). Below, we briefly outline some of these core principles agreed upon by experts in the field.

\section{Proximate vs Ultimate Causes and Host Defenses vs Pathogen Offences}

One of the core principles of evolutionary medicine is distinguishing between the mechanistic (proximate) and evolutionary (ultimate) explanations for a disease (Grunspan et al. 2018). The difference between these two explanations is often conveyed as the dichotomy between the questions "what is the disease" or "how does it form" versus the question of "why the disease exists in the first place" (Spocter and Strkalj 2007). Both mechanistic and evolutionary explanations are important to completing our understanding of the human body and disease vulnerability (Williams and Nesse 1991).

Building from this approach, it is also important to recognize that many signs and symptoms of disease may in fact form part of the body's natural defense mechanism (Ewald 1980). From this perspective the protective nature of host defenses, which include among other signs nausea, vomiting, pain, fatigue, and diarrhea, are distinguished from that of pathogen offenses (Williams and Nesse 1991). The challenge for the clinician is thus knowing when to interfere with these inherent host defenses as the cost of intervention while alleviating discomfort for the patient may result in the promotion of pathogen transmission and offenses. For example, studies of Shigellosis infection have demonstrated that diarrhea in these cases is in fact a host defense mechanism used by the body to reduce the contact time between the pathogen and the intestinal lining (DuPont and Hornick 1973). Thus, treatments which decrease the frequency and number of bowel movements (e.g., Lomotil therapy) are contraindicated in Shigellosis infection as they result in extended illness in the patient and are likely to contribute to the patient becoming a carrier of this infection (DuPont and Hornick 1973).

To think of it another way, one can consider this example as highlighting the importance of distinguishing between the immediate impact of a disease which is driven by the host defense response and its later impact which forms part of the pathogen offense. For example, a clinician might consider a fever as a (proximate) cause of an infection and in most cases would seek to treat this fever with fever-reducing drugs to spare the patient the immediate discomfort associated with the disease. However, several studies have shown that fever is a host defense mechanism and benefits the organism by decreasing viral replication rates in many pathogens while increasing the speed of immune reactions (Kluger 1979; Kluger et al. 1996). Thus, from an evolutionary medicine perspective, the reflex like tendency to administer fever-reducing drugs in most mild cases of fever is counterproductive as it diminishes the body's natural ability to combat infection (Kluger and Rothenburg 1979). It is, however, important to note that an evolutionary medicine perspective does not advocate that fever-reducing drugs should not be used at all as there are particular cases as in a high fever where the impacts on the patient might exceed the limits of the immune response and thus intervention is necessary (Trevathan et al. 2008). This is certainly the case for certain pathogens which are known to increase their reproductive fitness in response to fever (Ewald 1994). Another example of a host defense is the acute phase response, which results in a series of complex innate reactions shortly after tissue injury. As part of this defense mechanisms, there is the release of inflammatory cytokines (such as interleukin 6, tumor necrosis factor alpha, and interleukin 1 beta) which mediate the upregulation of acute phase protein, an important component of this systemic defense response, as well as several clinical signs which include fever, listlessness, and loss of appetite (Smith et al. 2013). The fact that these cytokines are found across vertebrate species suggests that the acute phase response is a universal defense mechanism shared by this group (Spocter and Strkalj 2007) and that the associated subcomponents to the response are likely to confer added defense to the organism (Weinberg 1984; Kluger and Rothenburg 1979; Hart 1985). 


\section{Sexual Selection and Reproductive Fitness}

The scope of evolutionary medicine has grown to include the consideration of several important evolutionary processes. Among this wide range of processes, most experts in the field agree that this includes the classic Darwinian process of natural selection but also the consideration of genetic drift, mutation, migration, and nonrandom mating, all of which are important for our understanding of disease (Grunspan et al. 2018). In addition, the influence of sexual selection and reproductive success are also considered important concepts in understanding the origins of disease. For instance, the reproductive fitness of the organism could be favored by natural selection at the expense of health and longevity or could similarly decrease in response to other factors as argued for humans (e.g., Westendorp and Kirkwood 1998). In addition, the influence of sexual selection might also differentially impact health risks and outcomes in males and females (e.g., Janicke et al. 2016). Sexual selection is known to have a significant impact on the epidemiology of sexually transmitted diseases (STDs) (Janicke and Morrow 2019). Stronger sexual selection in males results in males investing relatively more resources into mate acquisition at the expense of their own health and contributing toward riskier behavior in males (Zuk 2009).

\section{Constraints, Trade-Offs, and Life History Theory}

Several constraints might also prevent or inhibit the ability of natural selection to optimally shape human health and thus serve as an additional mechanism by which human susceptibility to disease might have evolved. These limits on natural selection include developmental, architectural, metabolic, or phylogenetic constraints (Spocter 2009) as well as trade-offs resulting from pleiotropy and mutations (Williams and Nesse 1991). For instance, one example of an architectural constraint known to have several clinical implications is the constraining influence of evolving bipedalism (Trevathan 2011). Humans are the only habitual mammalian biped, and those adaptations which make us uniquely suited to this form of locomotion have also made us susceptible to the occurrence of a range of clinical conditions including lower back pain and complications arising during childbirth (Spocter and Strkalj 2007). Furthermore, the evolution of bipedalism has also imposed constraints which have an impact on prenatal brain growth within the skull as the adult female is challenged with passing a relatively large head of a child through the relatively narrow pelvic outlet (Trevathan 2011).

Trade-offs in evolutionary medicine refer to the existence of linked changes between traits such that an evolutionary change increasing the fitness of one trait results in a decrease in fitness to another trait (Trevathan et al. 2008). In Neese and William (1991) articulation of Darwinian medicine, trade-offs were considered central to explaining disease vulnerability in evolutionary medicine and are intimately related to life history theory (Stearns 1989). Life history traits are shaped by natural selection and include traits such as the age of menarche and rate of senescence both of which have implications for human health and disease (Stearns 1989). In brief, one may understand the organizing principles of life history theory as stressing that there is only a finite amount of energy available for an organism's growth, maintenance, and reproduction (Stearns 1989). Thus, the allocation of energy budgets to either corresponding life stages (e.g., gestation, weaning, lifespan) or growth within body components (e.g., body growth versus brain growth) requires trade-offs between components. For instance, energy spent on child rearing to maturity comes at a cost to energy that could have been used for reproduction, and in a similar way, energy spent on evolving a large brain (a metabolically expensive tissue) comes at the cost to free energy that might have been used for other organ systems such as the gut Aiello and Wheeler 1995).

\section{Multiple Levels of Selection}

Human vulnerability to disease may also result from the conflicting/opposing force of selection acting at different (or multiple) levels of organization (e.g., at the level of the molecule, gene, cell, organism, kin, or population) (Williams and Nesse 1991). Prime examples of this include 
genetic conflicts and somatic selection in cancer. For example, the differential interests of competing genes (or gene networks) in the human immune response could result in a myriad of genetic conflicts as the organism mounts a defense against an invading pathogen (Levin and Bull 1994). This conflict is a result of the complex and tiered arrangement of the host's defenses (Spocter and Strakalj 2007). Thus, understanding these complex interactions requires considering the differential impacts of selection at each level. Some postulate that sexual reproduction exists primarily to increase variability through rapid genetic change in response to the competing influence of pathogens (Hamilton et al. 1990). Similarly, it is argued that a genetic conflict between male and female gametes is responsible for the vast amount of sperm required for fertilization and the complexity of the female reproductive tract (Wedekind 1994).

\section{Coevolution}

Evolutionary medicine is also concerned with the influence of coevolution in driving health and disease. Some examples include the establishment of an evolutionary arms race between a host and a pathogen (Ewald 1980), the establishment of symbiotic relationships such as those seen in the human gut microbiome (Williams and Nesse 1991), and the coevolutionary competition between bacteria resulting in antibiotic production (Davies and Davies 2010).

The effect of pathogens on the human body and their differing patterns of virulence (i.e., severity) have been the subject of much discussion in evolutionary medicine (e.g., Ewald 1980, 1988, and 1994). Society has become increasingly aware of differences in virulence between recent pathogenic threats (e.g., SARS-CoV2 versus Influenza A virus) and the importance of vaccination efforts and personal hygiene practices to ward off epidemic or pandemic spread (Ehreth 2003). Some have argued quite cogently that the development of vaccines is an area in modern medicine which could benefit most strikingly if an evolutionary perspective is adopted (Read et al. 1999). Earlier arguments looking at the virulence of pathogens had supported the view that pathogens will naturally evolve toward less virulent states, a so-called equilibrium state, striking a balance between host survivability, transmission, and virulence (Levin and Svanborg-Eden 1990). Subsequent studies have shown that the concept of an equilibrium state falls short of describing all potential pathogen-host interactions and a richer view of virulence dynamics has emerged (Levin and Pimentel 1981; Frank 1996; Ebert 1999; Ebert and Bull 2003). Ewald (1980) has shown that the influence of "selfish gene" mutations in benign pathogens may still result in an increase in virulence provided that the rate of pathogen replication and transmission is increased. From an evolutionary perspective, transmission and replication of the pathogens genetic material is the most important consideration, not the state of its host, and thus host maintenance only becomes a consideration in cases where transmission is slow (Ewald 1980).

A further consideration in the evolution of virulence has been observation that some pathogens are able to effect host behavior to enhance transmission and that these pathogens tend to progress toward greater states of virulence (Ewald 1988, 1994). While there are several striking examples of dramatic behavioral changes in hosts favoring pathogen transmission, such as the increased aggression and diminished fearlessness observed in hosts infected with rabies (Jackson 2016) or Toxoplasma (Berdoy et al. 2000) and parasitic flukes (Wickler 1976), it is important to keep in mind that other more subtle changes in behavior may also help facilitate pathogen transmission. For example, while speculative, one might postulate that the relatively late onset of symptoms and the differential mortality in younger individuals as observed in the recent SARSCoV2 pandemic might serve to enhance pathogen transmission, suggesting that this virus might continue to evolve toward increased virulence, impacting decisions on vaccine development. Mathematical modelling looking at the evolution of pathogen virulence has shown that vaccines that prevent infection may limit the virulence of the pathogen. However, those vaccines that only limit antitoxin immunity lead to increased prevalence and virulence (Gandon et al. 2001). In this 
regard, Read and colleagues (1991) have argued that rather than pursue the development of vaccines aimed at eliminating all forms/strains of a given virus, a more prudent and evolutionary informed approach would be to develop vaccines only against the most virulent strains of a virus, thus using mild forms of the virus as a means of conferring immunity. This approach is akin to that used in young children, where the child is infected with a mild strain of the virus through vaccination and from which subsequent immunity for all strains (including the more virulent ones) usually develops (Trevathan et al. 2008). Some argue that maintaining a coexistence with mild pathogenic strains is a more sustainable approach to vaccination, as a complete lack of exposure to a virus may leave a large sector of the population at risk to more virulent forms of a virus (Trevathan et al. 2008). It goes without saying that an awareness of host-pathogen interactions as viewed through the lens of evolutionary medicine is also critical to the way we address current or future healthcare crises both at the frontline as medical practitioners and biomedical scientists but also as a global community, mindful of how our actions (or inaction) could promote pathogen transmission.

\section{Evolutionary Mismatch/Adaptations to Novel Environments}

For practitioners of evolutionary medicine, one particularly important source of disease is that which one might call "diseases of modernity." These ailments, described as maladaptations, include diseases such as obesity, hypertension, type 2 diabetes, and back pain. It is hypothesized that these ailments arose as a result of a mismatch between the environments in which the human body evolved and that of our modern lifestyles to which our bodies have adapted to (Eaton et al. 1988; Eaton and Eaton 1991). Central to this hypothesis is the idea of an environment of evolutionary adaptiveness (i.e., an environment to which our bodies are most optimally adapted) (Irons 1998). Subsequent scientific discourse has seen the expansion of this idea away from the incorrect assumption that humans are optimally adapted to a single environment (e.g., a Paleolithic environment as initially proposed by Williams and Nesse 1991) and the acknowledgment that this mismatch may also result from migration between stable environments (Grunspan et al. 2018; Gluckman et al. 2016). The underlying principle is that there is a dichotomy between "past" and "present" such that our bodies (and minds) have not had enough time to adapt to our modern environments (Sharma 1998). For instance, one might consider obesity and its accompanying sequalae of hypertension and atherosclerosis as one example of a disease resulting from such an environmental mismatch. In comparison to Paleolithic communities, modern humans consume large amounts of sugars, salts, and fats (Eaton and Eaton 1991; Eaton et al. 1996; Nesse and Williams 1999), all of which were scarce and highly prized in Paleolithic communities but are relatively abundant in modern environments. Our brains, however, still perceive and process these stimuli as if we are in the Paleolithic, driving us toward acquiring larger quantities of these components to the detriment of our own health and exasperated by the reduction in human activity levels. Another example of this type of maladaptation is that of human drug dependency (Lende 2008), with comparative genomic studies indicating an interesting overlap in genes involved in addiction propensity and human self-domestication (Calvey 2019). In addition, human sleep disorders may also result from our modern environments. In primate evolution, we observe a transition from that of arboreal sleep to the building of nests that would secure a more efficient and longer sleeping time to humans sleeping on the ground, enhanced by the discovery and control of fire conferring security to our hominin ancestors (Nunn et al. 2016). The advent of electricity and industrialization made a significant impact on human sleep pattern, and one may argue that the speed of technological evolution and impact on human societal behavior has outpaced the speed of human biological adaption, explaining some of the myriad of sleep disorders (Deboer 2020) and, more commonly, insufficient sleep time, with all the associated health consequences. 


\section{Plasticity and Cultural Practices}

The impact of plasticity and cultural practices on human disease are two more recent additions to the field of evolutionary medicine. All organisms possess a general capacity for plasticity, for example, the phenotype of an organism may shift in the course of development as genes interact with varying environments (Lea et al. 2017). In evolutionary medicine, there is the acknowledgment that environmental factors may have an impact on human development resulting in changes to health and that plasticity itself is an adaptive mechanism under the influence of evolutionary processes (Lea et al. 2017; Grunspan et al. 2018). Especially important for evolutionary medicine are mechanisms that influence development in response to environmental cues detected during critical developmental periods (Lea et al. 2017). Cultural practices are also acknowledged to have a significant impact on human health and disease vulnerability. These cultural practices may influence evolution (e.g., of humans, pathogens, or other species within our environment) or influence medical practice (e.g., antibiotic, chemotherapy, or caesarean section frequency within a given population) (Grunspan et al. 2018). In terms of evolutionary medicine, cultural practices are considered an important non-Darwininian (i.e., non-genetic) trait and along with other epigenetic factors (e.g., Handel and Ramagopalan 2010) influence human health and disease in a Lamarckian manner.

\section{Conclusion}

The field of evolutionary medicine has contributed significantly toward our understanding of disease etiology and the evolutionary origins of human susceptibility to disease. While this perspective continues to gain interest among specialists, especially biomedical scientists, it is hoped that a growing set of clinicians might use the insight gained from evolutionary medicine to better address the healthcare needs of the communities they serve.

\section{Cross-References}

\author{
Evolution \\ Life History Theory \\ Medicine \\ Trade-offs
}

\section{References}

Aiello, L. C., \& Wheeler, P. (1995). The expensive tissue hypothesis: The brain and digestive system in human and primate evolution. Current Anthropology, 36(2), 199-221.

Alcock, J. (2012). Emergence of evolutionary medicine: Publication trends from 1991-2010. Journal of Evolutionary Medicine, 1, 235572.

Allison, A. C (1953). The sickle-cell trait in the Mediterranean area. Man. 53, 23-24.

Allison, A.C (1954). Notes on sickle-cell polymorphism. With statistical appendix by S. Maynard Smith. Ann Human Genet 19, 39-57.

Barnicot, N.A., Ikin, E.W., \& Mourant, A.E (1954). Les groups sanguins $\mathrm{ABO}$, MNNS et $\mathrm{Rh}$ des Touareg de l'Air. L'Anthropologie 53, 231-240.

Boyd, R., \& Silk, J (2009). How humans evolved, 5th Edition. Norton, New York.

Berdoy, M., Webster, J. P., \& Macdonald, D. W. (2000). Fatal attraction in rats infected with Toxoplasma gondii. Proceedings of the Royal Society of London - Series B: Biological Sciences, 267, 1591-1594.

Brace, C. L., Rosenberg, K. R., \& Hund, K. D. (1987). Gradual change in human tooth size in the late pleistocene and post pleistocene. Evolution, 41, 705-720.

Calvey, T. (2019). Human self domestication and the extended evolutionary synthesis of addiction: How humans evolved a unique vulnerability. Neuroscience, 419, 100-107.

Chakravarthy, M. V., \& Booth, F. W. (2004). Eating, exercise, and "thrifty" genotypes: Connecting the dots toward an evolutionary understanding of modern chronic diseases. Journal of Applied Physiology, 96, 3-10.

Cooper, M. D., \& Herrin, B. R. (2010). How did our complex immune system evolve? Nature Reviews. Immunology, 10, 2-U11.

Darwin, E. (1794-1796). Zoonomia; or The Laws of Organic Life, 2nd Corrected ed. London: printed for J. Johnson [Available from project Gutenberg, http: www.gutenberg.org/files/15707/15707-h/15707-h. $\mathrm{htm}]$

Davies, J., \& Davies, D. (2010). Origins and evolution of antibiotic resistance. Microbiology and Molecular Biology Reviews, 74(3), 417-433.

Deboer, T. (2020). Circadian regulations of sleep in mammals. Current Opinion in Physiology, 15, 1-7. 
DuPont, H. L., \& Hornick, R. B. (1973). Adverse effect of Lomotil therapy in shigellosis. Journal of the American Medical Association, 226(13), 1525-1528.

Eaton, S. B., \& Eaton, S. B. I. (1991). The evolutionary context of chronic degenerative diseases. In S. C. Stearns (Ed.), Evolution in health and disease (pp. 251-259). Oxford: Oxford University Press.

Eaton, S. B., Shostak, M., \& Konner, M. (1988). The paleolithic prescription. New York: Harper \& Row.

Eaton, S. B., Eaton, S. B., Konner, M. J., \& Shostak, M. (1996). An evolutionary perspective enhances understanding of human nutritional requirements. The Journal of Nutrition, 126, 1732-1740.

Ebert, D. (1999). The evolution and expression of parasite virulence. In S. C. Stearns (Ed.), Evolution in health \& disease. Oxford: Oxford University Press.

Ebert, D., \& Bull, J. J. (2003). Challenging the trade-off model for the evolution of virulence: Is virulence management feasible? Trends in Microbiology, 11, 15-20.

Ehreth, J. (2003). The global value of vaccination. Vaccine, 21(7 \& 8), 596-600.

Ewald, P. W. (1980). Evolutionary biology and the treatment of signs and symptoms of infectious disease. Journal of Theoretical Biology, 86, 169-176.

Ewald, P. W. (1988). Cultural vectors, virulence, and the emergence of evolutionary epidemiology. Oxford Surveys in Evolutionary Biology, 5, 215-245.

Ewald, P. W. (1994). Evolution of infectious disease. Oxford: Oxford University Press.

Frank, S. A. (1996). Models of parasite virulence. The Quarterly Review of Biology, 71, 37-78.

Gandon, S., Mackinnon, M. J., Nee, S., \& Read, A. F. (2001). Imperfect vaccines and the evolution of pathogen virulence. Nature, 414, 751-756.

Gluckman, P., Beedle, A., Buklijas, T., et al. (2016). Principles of evolutionary medicine. New York: Oxford University Press.

Grunspan, D. G., Nesse, R. M., Barnes, M. E., \& Brownell, S. E. (2018). Core principles of evolutionary medicine: A Delphi study. Evolution, Medicine, and Public Health, 1, 13-23.

Hamilton, W. D., Axelrod, R., \& Tanese, R. (1990). Sexual reproduction as an adaptation to resist parasites (a review). Proceedings of the National Academy of Sciences of the United States of America, 87, 3566-3573.

Handel, A. E., \& Ramagopalan, S. V. (2010). Is Lamarckian evolution relevant to medicine. BMC Medical Genetics, 11, 73.

Hart, B. L. (1985). Animal behavior and the fever response: Theoretical considerations. Journal of the American Veterinary Medical Association, 187, 998-1001.

Irons, W. (1998). Adaptively relevant environments versus the environment of evolutionary adaptedness. Evolutionary Anthropology, 6, 194-204.

Jackson, A. C. (2016). Diabolical effects of rabies encephalitis. Journal of Neurovirology, 22(1), 8-13.
Janicke, T., \& Morrow, E. H. (2019). Sexual selection. Evolution, Medicine, and Public Health, 2019(1), 36.

Janicke, T., Häderer, I. K., Lajeunesse, M. J., et al. (2016). Darwinian sex roles confirmed across the animal kingdom. Science Advances, 2, e1500983.

Jornvall, H. (1994). The alcohol dehydrogenase system. EXS, 71, 221-229.

Katzmarzyk, P. T., \& Leonard, W. R. (1998). Climatic influences on human body size and proportions: Ecological adaptations and secular trends. American Journal of Physical Anthropology, 106, 483-503.

Keller, M. C., \& Nesse, R. M. (2006). The evolutionary significance of depressive symptoms: Different adverse situations lead to different depressive symptom patterns. Journal of Personality and Social Psychology, 91, 316.

Kluger, M. J. (1979). Fever, its biology, evolution, and function. Princeton: Princeton University Press.

Kluger, M. J., \& Rothenburg, B. A. (1979). Fever and reduced iron: Their interaction as a host defense response to bacterial infection. Science, 203, 374-376.

Kluger, M. J., Kozak, W., Conn, C. A., Leon, R. L., \& Soszynski, D. (1996). The adaptive value of fever. Infectious Disease Clinics of North America, 10, 1-20.

Lea, A. J., Tung, J., Archie, E. A., \& Alberts, S. C. (2017). Developmental plasticity: Bridging research in evolution and human health. Evolution, Medicine, and Public Health, 2017(1), 162-175.

Lende, D. H. (2008). Evolution and modern behavioural problems: The case of addiction. In W. R. Trevathan, E. O. Smith, \& J. J. McKenna (Eds.), Evolutionary medicine and health: New perspectives. Oxford: Oxford University Press.

Levin, B. R., \& Bull, J. J. (1994). Short-sighted evolution and the virulence of pathogenic microorganisms. Trends in Microbiology, 2, 76-81.

Levin, S., \& Pimentel, D. (1981). Selection of intermediate rates of increase in parasite-host systems. The American Naturalist, 117, 308-315.

Levin, B. R., \& Svanborg-Eden, C (1990). Selection and evolution of virulence in bacteria: an ecumenical excursion and modest suggestion. Parasitology, 100 Suppl, S103-S115.

Litman, G. W., \& Cooper, M. D. (2007). Why study the evolution of immunity? Nature Immunology, 8 , 547-548.

Livingston, F. B (1958). Anthropological implications of sickle cell gene distribution in West Africa. Am Anthropol 60(3), 533-562.

Matthews, S. B., Waud, J. P., Roberts, A. G., \& Campbell, A. K. (2005). Systemic lactose intolerance: A new perspective on an old problem. Postgraduate Medical Journal, 81, 167-173.

Merlo, L. M., Pepper, J. W., Reid, B. J., et al. (2006). Cancer as an evolutionary and ecological process. Nature Reviews. Cancer, 6, 924-935.

Morton, D. J (1926). The relation of evolution to medicine. Science 64(1660), 394-396. 
Nesse, R. (1999). What Darwinian medicine offers psychiatry. In Evolutionary Medicine, W. R. Trevathan, J. J. McKenna and E. O. Smith. New York, Oxford University Press, pp. 351-374.

Nesse, R. M., \& Williams, G. C. (1999). On Darwinian medicine. Life Sci Res, 3, 1-32.

Nunn, C. L., Samson, D. R., \& Krystal, A. D. (2016). Shining evolutionary light on human sleep and sleep disorders. Evolution, Medicine, and Public Health, 1, 227-243.

Ruff, C. B. (2002). Variation in human body size and shape. Annual Review of Anthropology, 31, 211-232.

Ruhli, F. J., \& Henneberg, M. (2013). New perspectives on evolutionary medicine: The relevance of microevolution for human health and disease. BMC Medicine, 11, 115.

Read, A. F., Aaby, P., Antia, R., Ebert, D., Ewald, P. M., Gupta, S., Holmes, E. C., Sasaki, A., Shields, D. C., Taddei, F., \& Moxon, R. E (1999). What can evolutionary biology contribute to understanding virulence? In: Evolution in Health and Disease. Stearns (ed.). Oxford, UK: Oxford University Press, pp 205-218.

Schmid Hempel, P. (2011). Evolutionary parasitology the integrated study of infections, immunology, ecology, and genetics. New York: Oxford University Press.

Schwidetzky, I. (1962). Das Grazilisierungsproblem. Homo, 13, 188-195.

Sharma, A. (1998). The thrifty genotype hypothesis and its implications for the study of complex genetic disorders in man. Journal of Molecular Medicine, 76, 568-571.

Smith, G. S., Walter, G. L., \& Walker, R. M. (2013). Clinical pathology in non-clinical toxicology testing. In W. M. Haschek, C. G. Rousseaux, \& M. A. Wallig (Eds.), Haschek \& Rousseaux's handbook of toxicologic pathology (3rd ed.). San Diego: Academic Press.

Spocter, M. A (2009). The Panglossian paradigm revisited. The role of non-adaptive mechanism in hominid brain and body size evolution. Ph.D. Dissertation, University of the Witwatersrand, Johannesburg.

Spocter, M. A., Strkalj, G. (2007). Darwinian medicine. an evolutionary perspective on health and disease. $S$ Afr Med J 97(11), 1044-1046.
Stearns, S. C. (1989). Trade-offs in life-history evolution. Functional Ecology, 3, 259-268.

Stearns, S., Ackermann, M., Doebeli, M., et al. (2000). Experimental evolution of aging, growth, and reproduction in fruitflies. Proceedings of the National Academy of Sciences of the United States of America, 97, 3309-3313.

Straub, R. H. (2012). Evolutionary medicine and chronic inflammatory state - Known and new concepts in pathophysiology. Journal of Molecular Medicine, 90, 523-534.

Trevathan, W. R. (2011). Human birth: An evolutionary perspective. Piscataway: Transaction Publishers.

Trevathan, W. R., Smith, E. O., \& McKenna, J. J. (2008). Introduction and overview of evolutionary medicine. In W. R. Trevathan, E. O. Smith, \& J. J. McKenna (Eds.), Evolutionary medicine and health: New perspectives. Oxford: Oxford University Press.

Trevathan, W (2010). Ancient bodies, modern lives: How evolution has shaped women's health. Oxford University Press.

Wedekind, C. (1994). Mate choice and maternal selection for specific parasite resistances before, during, and after fertilization. Philosophical Transactions of the Royal Society of London. Series B, Biological Sciences, 346, 303-311.

Weinberg, E. D. (1984). Iron withholding: A defense against infection and neoplasia. Physiological Reviews, 64, 65-102.

Westendorp, R. G., \& Kirkwood, T. B. (1998). Human longevity at the cost of reproductive success. Nature, 396(6713), 743-746.

Wickler, W. (1976). Evolution-oriented ethology, kin selection, and altruistic parasites. Zeitschrift für Tierpsychologie, 42, 206-214.

Williams, G. C., \& Nesse, R. M. (1991). The dawn of Darwinian medicine. The Quarterly Review of Biology, $66,1-22$.

Zuk, M. (2009). The sicker sex. PLoS Pathogens, 5, e1000267. 